\title{
Feasibility and accuracy of tissue characterization with dual source computed tomography
}

\author{
Joanne K. Van Abbema, Arjen Van der Schaaf, Wisnu Kristanto, \\ Jaap M. Groen, Marcel J.W. Greuter*
}

University Medical Center Groningen, PO Box 30.001, Groningen, Netherlands

Received 12 July 2010; received in revised form 24 December 2010; accepted 22 January 2011

Available online 18 February 2011

\section{KEYWORDS \\ Dual energy; \\ Computed tomography; \\ Tissue characterization; \\ Electron density; \\ Effective atomic \\ number}

\begin{abstract}
Purpose: To evaluate the feasibility and accuracy of a model for tissue characterization with dual source computed tomography (DSCT).

Methods and Materials: A model for tissue characterization in CT was used with a parameterization of linear attenuation coefficients. Sixteen chemical substances with effective atomic numbers between 5.21 and 13.08 and electron densities between 2.20 and $4.12 \times 10^{23}$ electrons $/ \mathrm{cm}^{3}$ were scanned at energies of 80 and $140 \mathrm{kV}$ on a DSCT. From the reconstructed dual energy data sets, effective atomic numbers and electron densities of the substances were calculated.

Results: Our presented model using DSCT approximated the effective atomic numbers and effective electron densities of 16 substances very well. The measured effective atomic numbers deviated $3.4 \pm 6.8 \%\left(R^{2}=0.994\right)$ from theoretical effective atomic numbers. In addition, measured effective electron densities deviated $-0.6 \pm 2.2 \%\left(R^{2}=0.999\right)$ from theoretical effective electron densities.

Conclusion: Effective atomic numbers and effective electron densities can be determined with a high accuracy with DSCT. Therefore the model can be of potential benefit for clinical applications of quantitative tissue characterization with DSCT.

(c) 2011 Associazione Italiana di Fisica Medica. Published by Elsevier Ltd. All rights reserved.
\end{abstract}

\section{Introduction}

Computed tomography (CT) is established as an excellent imaging technique for anatomy and pathology in various clinical areas. High resolution, three dimensional image sets can be acquired with CT using $x$-ray beams in the energy range of $80-140 \mathrm{kV}$ [1]. In addition, image sets can be acquired at multiple energies to enable dual energy computed tomography (DECT) [2]. DECT can be used to differentiate between different materials. This differentiation of materials is

\footnotetext{
* Corresponding author.

E-mail address: m.j.w.greuter@rad.umcg.nl (M.J.W. Greuter).
} 
reported in various clinical areas such as the liver [3], mineral bone content [4] and pulmonary nodules [5], using different imaging systems, such as a CT brain scanner [6] and whole body CT $[7,8]$.

With the introduction of dual source computed tomography (DSCT) renewed interest in dual energy imaging surfaced throughout the radiological community [9]. DSCT enabled imaging with two energies simultaneously, whereas two separate scans were required with older CT scanners. New applications for DECT were reported such as tissue characterization of the heart $[10,11]$, the vascular system [12], urinary stones [13-19], postmortem studies [20], ligaments [21] and coronary stent patency [22].

All these studies provide tissue characterization based upon the difference in Hounsfield (HU) value at the two energies used in scanning. However DECT enables users to calculate the effective atomic number and effective electron density of substances [6,23-31]. This yields a more precise tissue characterization than using $\mathrm{HU}$ values.

In this paper we applied this technique to DSCT through a model. Therefore, the aim of this study was to evaluate the feasibility and accuracy of our model for tissue characterization with DSCT.

\section{Theory}

To obtain the effective atomic number and effective electron density of an unknown substance we used the following model for calculating these parameters.

As a first step the linear attenuation coefficient $\mu$ of photons is expressed by:

$\mu=\rho\left[\sigma_{\tau}+\sigma_{R}+\sigma_{C}\right]$

where $\sigma_{\tau}, \sigma_{R}$ and $\sigma_{C}$ are the atomic cross sections for photoelectric absorption, coherent Rayleigh and incoherent Compton scattering respectively, and $\rho$ is the atomic density. We approximate the cross sections for the energy range relevant for medical CT applications by: $\sigma_{\tau}=a E^{-b} Z^{c}$

$\sigma_{R}=d E^{-f} Z^{g}$

$\sigma_{C}=h e^{-j E} Z^{k}$

where $E$ is the energy of the photons and $Z$ the atomic number of the material. Furthermore the nine parameters $(a, b, c, d, f, g, h, j$, and $k$ ) are obtained from literature (see materials and methods section).

By scanning a substance at two distinct effective energies $E_{1}$ and $E_{2}$, the ratio of the linear attenuation coefficients $\mu_{E 1}$ and $\mu_{E 2}$, derived from the measured $H U$ values can be used to estimate the measured atomic number $(\widehat{Z})$ by numerically solving to $\widehat{Z}$ :

$\frac{\mu_{E 1}}{\mu_{E 2}}=\frac{a E_{1}^{-\mathrm{b}} \widehat{Z}^{c}+d E_{1}^{-f} \widehat{Z}^{g}+h e^{-j E_{1}} \widehat{Z}^{k}}{a E_{2}^{-\mathrm{b}} \widehat{Z}^{c}+d E_{2}^{-f} \widehat{Z}^{g}+h e^{-j E_{2}} \widehat{Z}^{k}}$

and the measured electron density $\left(\widehat{\rho}_{e}\right)$ can be expressed by:

$\widehat{\rho}_{e}=\frac{\mu_{E_{1}} \widehat{Z}}{a E_{1}^{-b} \widehat{Z}^{c}+d E_{1}^{-f} \widehat{Z}^{g}+h e^{-j E_{1}} \widehat{Z}^{k}}$

To assess the measured results, the theoretical effective atomic number $\left(Z_{E}^{\prime}\right)$ of the chemical substances is given by [32]:

$$
Z_{E}^{\prime}=\frac{\sum_{i=1}^{N} f_{i} A_{i}\left(\frac{\mu}{\rho}\right)_{i, E}}{\sum_{i=1}^{N} f_{i} A_{Z_{i}}\left(\frac{\mu}{\rho}\right)_{i, E}}
$$

where $f_{i}$ is the atomic fraction of element $i$ with atomic mass number $A_{i}, i$ runs over all $N$ elements in the substance and $(\mu / \rho)_{i, E}$ is the corresponding mass attenuation coefficient at energy $E$ as obtained from literature [33]. Finally, the theoretical effective electron density is given by:

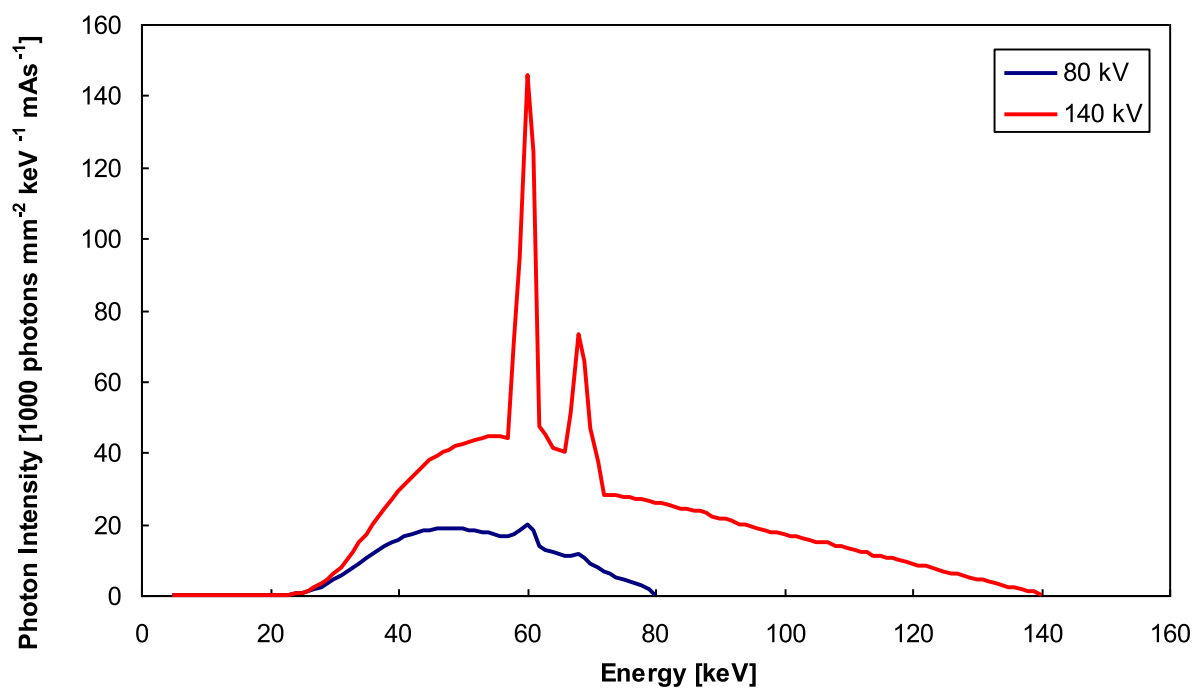

Figure 1 Output spectra for a dual source CT system (SOMATOM Definition) at tube voltages of 80 and $140 \mathrm{kV}$. Spectra provided by Siemens Medical Solutions, Forchheim, Germany were measured in air with a prefiltration of 2 mm aluminum and corrected to obtain the spectra for filtration of $3 \mathrm{~mm}$ aluminum and $0.9 \mathrm{~mm}$ titanium present in the SOMATOM Definition [45]. 
Table 1 Atomic cross sections as given in Eq (2), (3) and (4) with the corresponding fitting parameters determined from tabulated atomic cross sections [33] for $6 \leq Z \leq 20$ and $50 \leq E \leq 100 \mathrm{keV}$. Confidence intervals of the parameter fits are given as $\pm 1 S D$.

\begin{tabular}{llll}
\hline Cross section [barns/atom] & constant [barns/atom] & Energy dependence & Z dependence \\
\hline$\sigma_{\tau}$ & $a=22.3 \pm 1.1$ & $b=3.302 \pm 0.002$ & $c=4.62 \pm 0.02$ \\
$\sigma_{\mathrm{R}}$ & $d=3.71 \pm 0.27$ & $f=1.856 \pm 0.007$ & $g=2.60 \pm 0.02$ \\
$\sigma_{\mathrm{C}}$ & $h=0.672 \pm 0.003$ & $j=0.00197 \pm 0.00004$ & $k=0.939 \pm 0.003$ \\
\hline
\end{tabular}

$\rho_{e}^{\prime}=N_{A} \cdot \rho_{m} \cdot \sum_{i=1}^{N} f_{i}\left(\frac{Z}{A}\right)_{i}$

\section{Materials and methods}

\section{Method to determine the fitting parameters to approximate the cross section}

Tabulated atomic cross section data of relevant values of $Z$ [33] were plotted for the energy range of clinical CT to determine the fitting parameters of Eqs (2)-(4). For this, the effective energies of the dual source CT were determined as 51.93 and $69.28 \mathrm{keV}$ (for a tube voltage of 80 and $140 \mathrm{kV}$ respectively) by calculating the weighted mean energy of the polyenergetic $x$-ray spectrum provided by the manufacturer (Fig. 1). The parameters $b$, $f$ and $j$ were calculated using cross section data of oxygen in the energy range of $50-100 \mathrm{keV}$. The parameters $c, g$ and $k$ were calculated at a mean effective energy of $60.61 \mathrm{keV}$ (mean of 51.93 and $69.28 \mathrm{keV}$ ) and for atomic numbers ranging from 6 to 20. Finally, the parameters $a$, $d$ and $h$ were determined at the cross section of oxygen at $60.61 \mathrm{keV}$.

\section{Experimental setup and data analysis}

16 substances (Table 2) were scanned in glass and plastic bottles with a diameter of approximately 6.5 and $3.4 \mathrm{~cm}$ respectively on a dual source CT system (SOMATOM
Definition, Siemens Medical Solutions, Forchheim, Germany) [9] (Fig. 2). The bottles were aligned in the centre of the bore in the $z$-direction and were scanned in air. The scans were performed at $80 \mathrm{kV}\left(E_{2}\right)$ and $140 \mathrm{kV}\left(E_{1}\right)$ in spiral mode with a collimation of $2 \times 32 \times 0.6 \mathrm{~mm}$. After each scan, the images were reconstructed with a slice thickness of $0.6 \mathrm{~mm}$ and an increment of $0.4 \mathrm{~mm}$ with a standard smooth B30f reconstruction kernel with a field of view of $10 \mathrm{~cm}$. The reconstructed data sets were analyzed using Matlab (The MathWorks, Natick, MA, USA). For the analysis, $\mu$-maps were calculated from coronal plane reconstructions of the CT images using the Hounsfield equation $\mu_{\mathrm{s}}=\mu_{w}(1+\mathrm{HU} /$ 1000), where the linear attenuation coefficients of water were approximated by:

$\mu_{w}=\frac{\rho_{e, w}^{\prime}\left(a E^{-b} Z_{w}^{\prime c}+d E^{-f} Z_{w}^{\prime g}+h e^{-j E} Z_{w}^{\prime}{ }^{k}\right) \cdot 10^{-24}}{Z_{w}^{\prime}}$

where $\rho^{\prime}{ }_{e, w}=3.343 \times 10^{23} \mathrm{e} / \mathrm{cm}^{3}$ and $Z^{\prime}{ }_{w}=7.352$ and 7.287 at 51.93 and $69.28 \mathrm{keV}$ respectively.

Measured effective atomic numbers were calculated in the range of $1-30$ by numerically solving Eq (5) to $\widehat{Z}$, setting the difference between the left (ratio $\mu_{E 1} / \mu_{E 2}$ ) and right part to zero. Measured effective electron densities $\widehat{\rho}_{e}$ were calculated by Eq (6) using $\mu_{E 1}$ and $\widehat{Z}$ values as measured. These values for $\hat{Z}$ and $\hat{\rho}_{e}$ were determined on a voxel by voxel basis from the calculated $\mu$-maps. To reduce noise in the $\widehat{Z}$ and $\widehat{\rho}_{e}$ maps, for $\mu_{E 2}$ values smaller than $0.01 \mathrm{~cm}^{-1} \widehat{Z}$ were set to zero. The mean $\widehat{Z}$ and $\widehat{\rho}_{e}$ and standard deviation for each substance were measured by drawing an ellipse

Table 2 The 16 substances used to assess the model with their calculated effective atomic numbers $\left(Z^{\prime}\right)$ at $51.93,60.61$ and $69.28 \mathrm{keV}$, measured effective atomic numbers $(\widehat{Z})$ and deviation from $Z^{\prime}$ at $60.61 \mathrm{keV}$.

\begin{tabular}{|c|c|c|c|c|c|}
\hline Substance & $Z^{\prime} 51.93 \mathrm{keV}$ & $\mathrm{Z}^{\prime} 60.61 \mathrm{keV}$ & $\mathrm{Z}^{\prime} 69.28 \mathrm{keV}$ & $\widehat{Z}$ & Error $\widehat{Z}[\%]$ \\
\hline Pentane & 5.223 & 5.208 & 5.195 & $5.75 \pm 1.28$ & 10.4 \\
\hline Hexane & 5.241 & 5.226 & 5.214 & $5.68 \pm 1.31$ & 8.6 \\
\hline Heptane & 5.254 & 5.240 & 5.227 & $5.82 \pm 1.25$ & 11.1 \\
\hline Decane & 5.278 & 5.264 & 5.252 & $5.78 \pm 1.18$ & 9.8 \\
\hline Methanol & 6.525 & 6.479 & 6.447 & $6.87 \pm 0.86$ & 6.1 \\
\hline Ethanol & 6.179 & 6.137 & 6.108 & $6.42 \pm 1.01$ & 4.6 \\
\hline 1-Propanol & 5.988 & 5.951 & 5.925 & $6.52 \pm 0.90$ & 9.5 \\
\hline 2-Propanol & 5.988 & 5.951 & 5.925 & $6.41 \pm 0.96$ & 7.7 \\
\hline polyethyleenglycol 200 & 6.68 & 6.639 & 6.611 & $6.89 \pm 0.59$ & 3.8 \\
\hline Glycerol & 6.733 & 6.695 & 6.668 & $6.98 \pm 0.56$ & 4.2 \\
\hline$\beta-D(+)$ glucose $(50 \%)$ & 7.187 & 7.149 & 7.122 & $7.45 \pm 0.48$ & 4.3 \\
\hline distilled water & 7.352 & 7.314 & 7.287 & $7.48 \pm 0.55$ & 2.3 \\
\hline $\mathrm{CaCl}_{2}\left(\mathrm{H}_{2} \mathrm{O}\right)_{2}(8.11 \%)$ & 9.31 & 8.891 & 8.607 & $8.80 \pm 0.39$ & -1.0 \\
\hline $\mathrm{CaCl}_{2}\left(\mathrm{H}_{2} \mathrm{O}\right)_{2}(16.85 \%)$ & 10.717 & 10.109 & 9.677 & $9.53 \pm 0.37$ & -5.7 \\
\hline $\mathrm{CaCl}_{2}\left(\mathrm{H}_{2} \mathrm{O}\right)_{2}(26.32 \%)$ & 11.78 & 11.081 & 10.564 & $10.19 \pm 0.31$ & -8.0 \\
\hline $\mathrm{CaCl}_{2}\left(\mathrm{H}_{2} \mathrm{O}\right)_{2}(60 \%)$ & 13.821 & 13.084 & 12.494 & $11.43 \pm 0.25$ & -12.6 \\
\hline
\end{tabular}



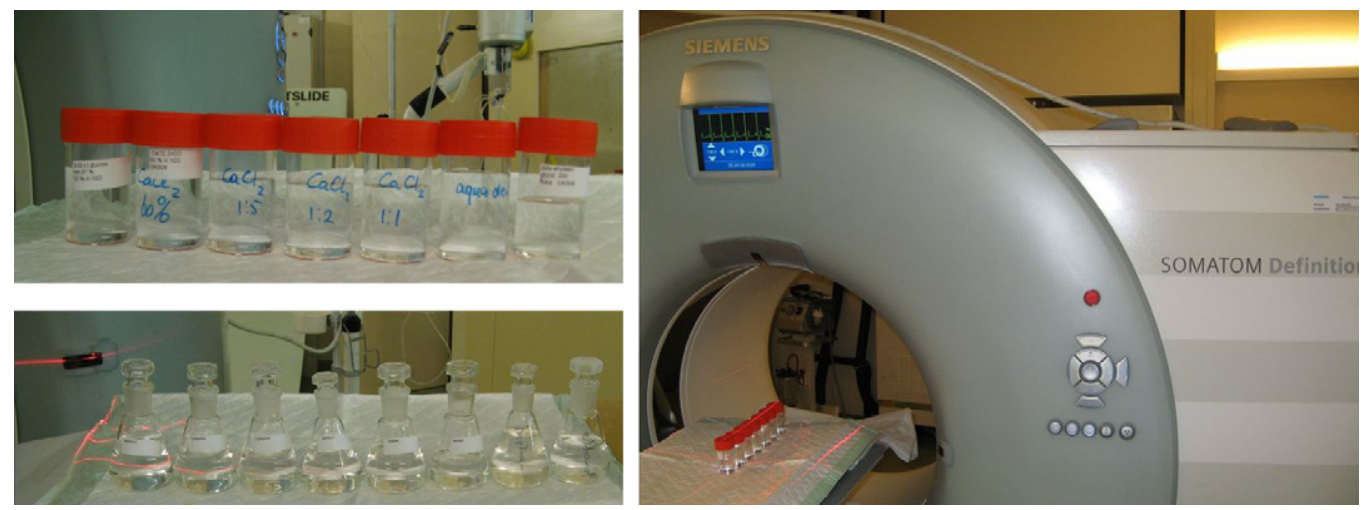

Figure 2 Experimental setup of the assessment experiment on the dual source CT.

shaped region of interest (ROI) with an area of approximately $3.8 \mathrm{~cm}^{2}$.

\section{Statistics}

All measurements were considered to be normally distributed. Mean \pm standard deviation were given for each measurement. In the calculated effective electron densities of the mixtures, the errors were determined by \pm the standard deviation of the measured mass densities. Fitting parameters were determined using a least square method and errors and Pearsons correlation coefficients $\left(R^{2}\right)$ were calculated. Regression analyses were performed on the results using a least square method and the $R^{2}$ was calculated.

\section{Results}

\section{Approximation of the linear attenuation}

The parameters $a, b, c, d, f, g, h, j$ and $k$ were calculated (Table 1) to approximate the atomic cross sections for photoelectric absorption, coherent Rayleigh and incoherent Compton scattering, given in Eqs (2)-(4). With the obtained fitting parameters, the function in Eq (5) was plotted for atomic numbers from 1 to 100 (Fig. 3), showing a steep gradient for $\mathrm{Z}$ between 3 and 20 .

\section{Data analysis}

$\mu$-maps were calculated from coronal plane reconstructions of CT images using values for $\mu_{\mathrm{w}}$ obtained with Eq (9) of 0.221 and $0.193 \mathrm{~cm}^{-1}$ at respectively 51.93 and $69.28 \mathrm{keV}$ (Fig. 4). Thereafter, $\widehat{Z}$-maps (Fig. 5) and $\widehat{\rho}_{e}$-maps (Fig. 6) were obtained from the $\mu$-maps.

\section{Measured effective atomic numbers and effective electron densities}

Measured effective atomic numbers deviated $3.4 \pm 6.8 \%$ from the calculated effective atomic numbers at $60.61 \mathrm{keV}$ $\left(R^{2}=0.994\right)$ (Table 2, Fig. 7). The maximum deviation was $-12.6 \%$. Measured effective electron densities deviated $-0.6 \pm 2.2 \%$ from the calculated effective electron densities $\left(R^{2}=0.999\right)$ (Table 3, Fig. 8). The maximum deviation was $+5.7 \%$.

\section{Discussion}

Our presented model using DSCT approximated the effective atomic numbers and effective electron densities of 16 substances very well. The measured effective atomic numbers between 5.21 and 13.08 deviated $3.4 \pm 6.8 \%$ from theoretical effective atomic numbers. In addition, measured effective electron densities between 2.20 and $4.12 \times 10^{23}$ electrons $/ \mathrm{cm}^{3}$ deviated $-0.6 \pm 2.2 \%$ from theoretical effective electron densities.

When the results of our model are compared to earlier studies similar results are observed. An agreement of $1 \%$ was reported for a theoretical model on effective electron densities compared to experimental data using monochromatic x-rays with energies of 40,70 and $80 \mathrm{keV}$ [23]. An agreement of $3.7 \%$ and $3.1 \%$ (mean errors) was reported for a Monte Carlo model on effective atom numbers and effective electron densities using polychromatic $x$-rays from a single source CT scanner [24]. Similar results have been reported using a two-slice multi-detector CT scanner [34]. An agreement of $2 \%$ was reported on high atomic number materials using an iterative computer model [25]. Heismann et al. used a 4-slice CT system on 12 substances also without a scattering phantom and reported an accuracy in the calculation of the effective atom number ranging from -4.4 to $+1.4 \%$ (mean $0.1 \%$ ) and of the effective electron density

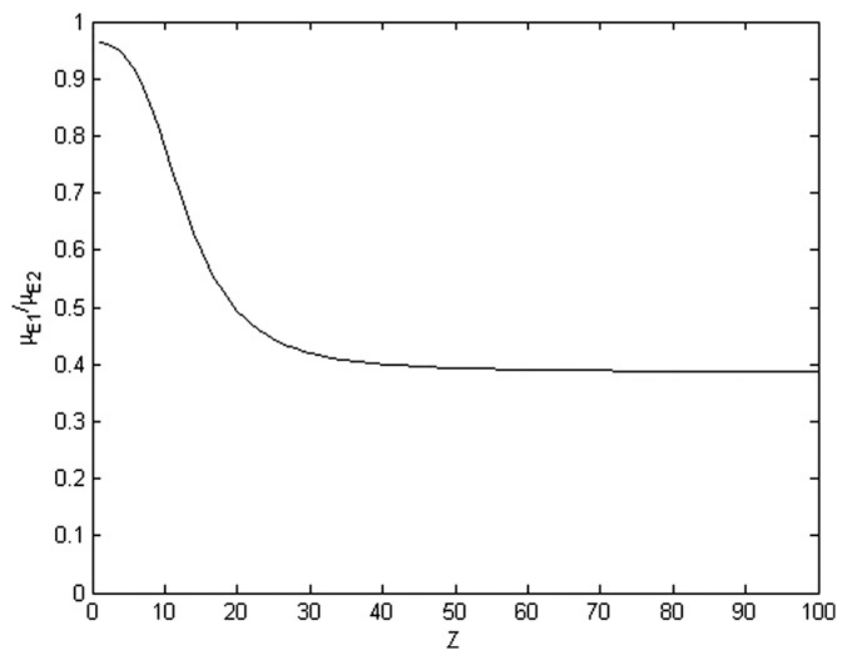

Figure 3 Ratio function $\mu_{E 1} / \mu_{E 2}$ of Eq (5) versus Z. 
a

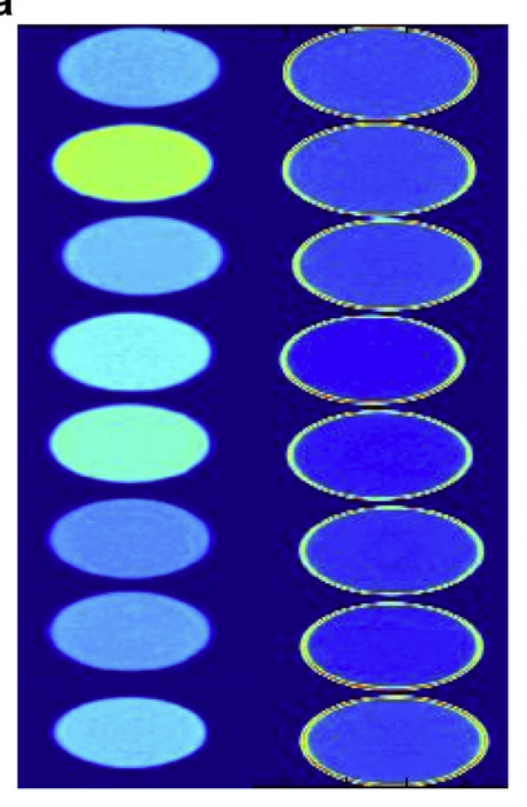

C

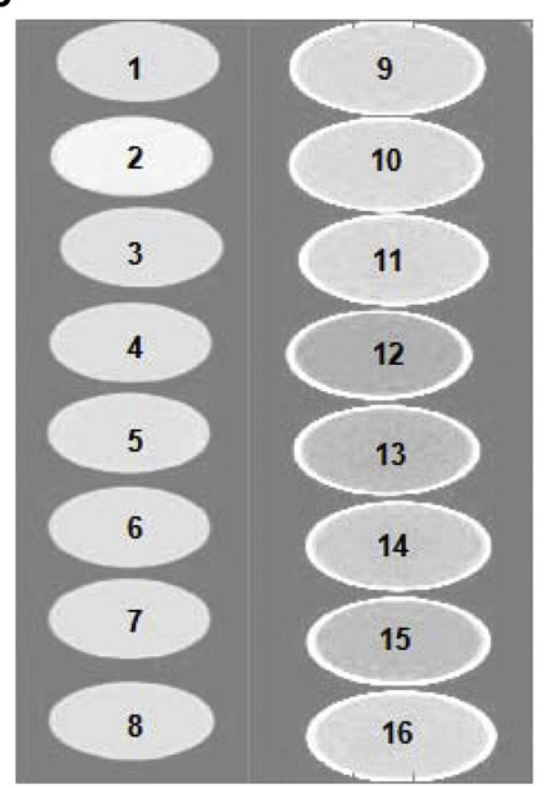

b

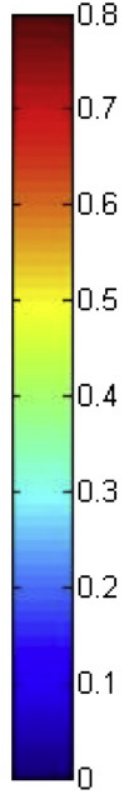

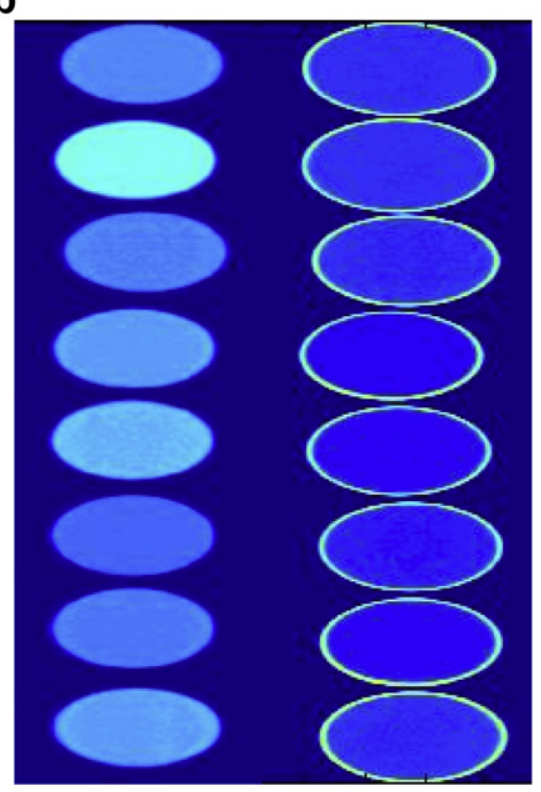

1. $\beta-D(+)$ glucose $(50 \%)$

2. $\mathrm{CaCl}_{2}\left(\mathrm{H}_{2} \mathrm{O}\right)_{2}(60 \%)$

3. $\mathrm{CaCl}_{2}\left(\mathrm{H}_{2} \mathrm{O}\right)_{2}(8.11 \%)$

4. $\mathrm{CaCl}_{2}\left(\mathrm{H}_{2} \mathrm{O}\right)_{2}(16.85 \%)$

5. $\mathrm{CaCl}_{2}\left(\mathrm{H}_{2} \mathrm{O}\right)_{2}(26.32 \%)$

6. distilled water

7. polyethyleenglycol 200

8. Glycerol

9. Methanol

10. 1-Propanol

11. 2-Propanol

12. Pentane

13. Hexane

14. Decane

15. Heptane

16. Ethanol

Figure 4 Calculated $\mu$-maps from coronal plane reconstructions of CT images at $80 \mathrm{kV}$ (a) and $140 \mathrm{kV}$ (b) and legend of the shown substances (c). Units are in $\mathrm{cm}^{-1}$.

ranging from -2.6 to $+2.6 \%$ (mean $-0.4 \%$ ) [29]. Similar results have been reported by Mahnken et al. using a 4-slice CT system on 44 samples obtained from diagnostic and therapeutic punctures [28]. All these results are in good agreement with our results using polychromatic $x$-rays with effective energies for 80 and $140 \mathrm{kV}$ on a DSCT system.

In this study effective atomic numbers and effective electron densities could be derived with a high accuracy on DSCT. However, the chemical substances that were scanned were not surrounded by a body phantom and therefore, the influence of scattering and beam hardening on the obtained images was minimized. We estimate that the influence of beam hardening on the measured linear attenuation coefficients is in the order of $\pm 5 \%$ [39]. This uncertainty is in the same order of magnitude as the standard deviation in the measured effective atomic numbers. However, this uncertainty is relatively large compared to the standard deviation in the measured electron effective densities. A study on 17 chemical substances surrounded by a solid water phantom however showed results which are in good accordance to our results [26]. Furthermore, it can be argued that our experiment 


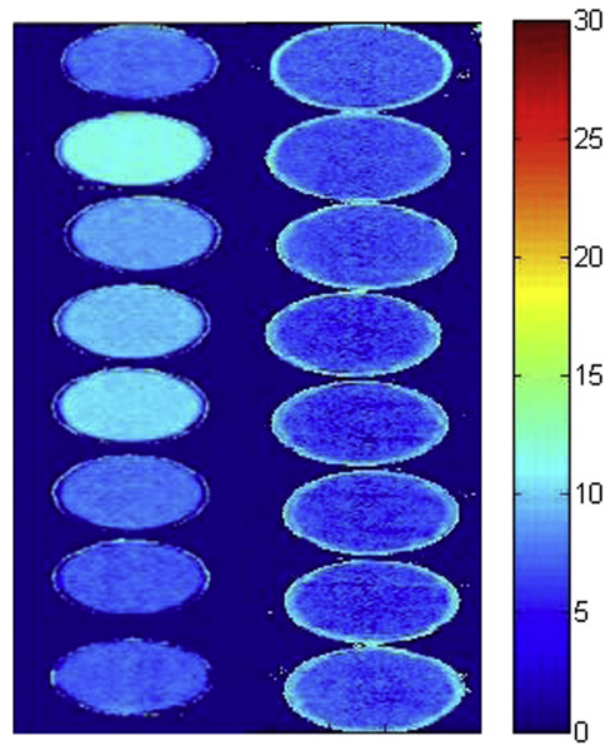

Figure $5 \hat{Z}$-maps obtained from coronal plane $\mu$-maps.

was not completely scatter-free, the bottles in which the substances were scanned showed some scatter effects, albeit minor. Therefore we can conclude that we have shown the feasibility and accuracy of the used model and that in following research influencing factors such as scattering and beam hardening have to be assessed.

The approximation of the linear attenuation coefficient, to extract the effective atomic numbers and electron densities from CT images, is limited by the energy and Z dependence of the fitting parameters [35]. It has been shown that no single formula of the form $Z^{a} E^{-b}$ can describe the variation of photoelectric absorption and coherent Rayleigh scattering over the range $30-100 \mathrm{keV}$ for $\mathrm{Z}$ between 1 and 20 to the accuracy needed [36]. However, using the obtained fitting parameters, the approximated individual cross sections deviated less than $8.1 \%$ from tabulated atomic cross sections for Z ranging from 6 to 20

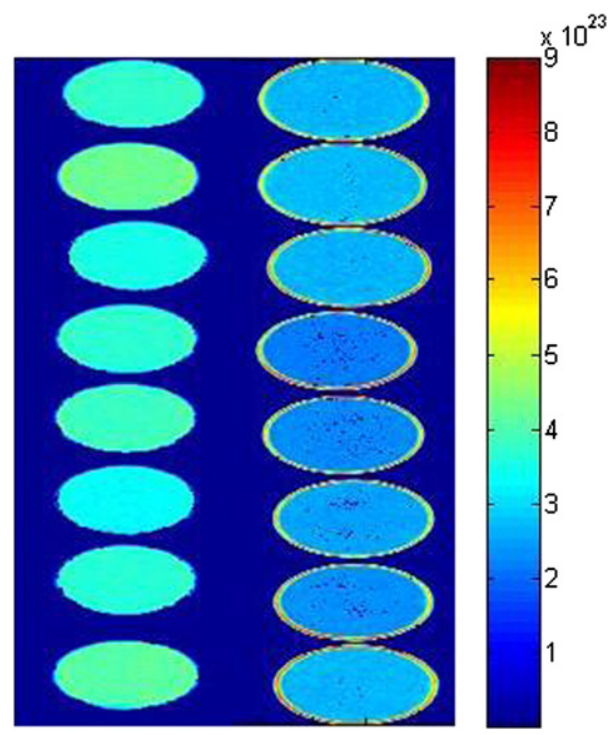

Figure $6 \hat{\rho}_{e}$-maps obtained from coronal plane $\mu$-maps and $\widehat{Z}$-maps. Units are in electrons per $\mathrm{cm}^{3}$.

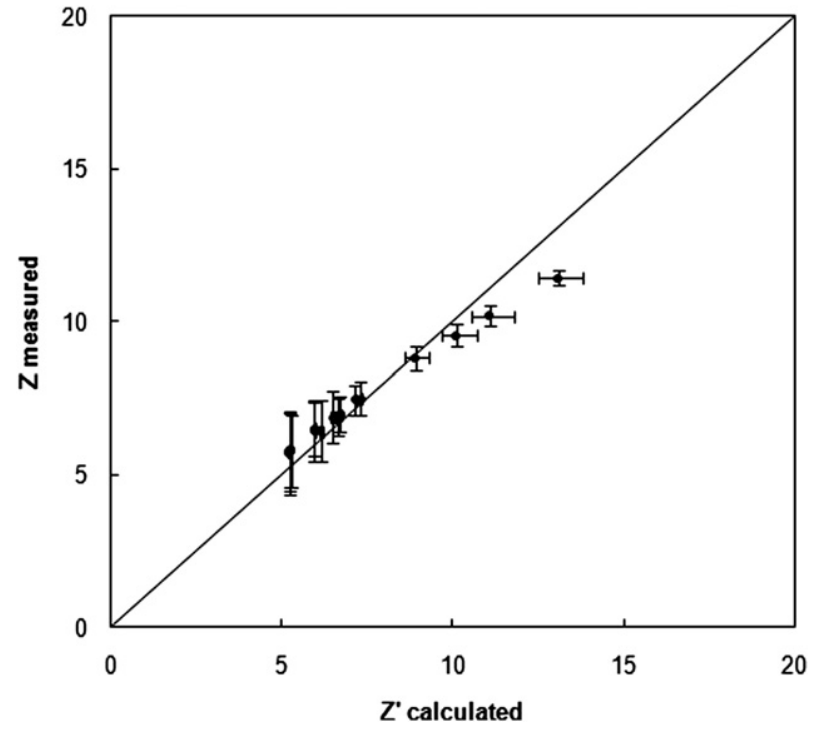

Figure 7 Measured effective atomic numbers ( $\mathrm{Z}$ measured, $\widehat{Z}$ ) of all substances (Table 2 ) versus the corresponding calculated effective atomic numbers ( $Z^{\prime}$ calculated). Calculated effective atomic numbers ( $Z^{\prime}$ calculated) for $60.61 \mathrm{keV}$ are given by data points, plus and minus errors are given by $Z^{\prime}$ at $51.93 \mathrm{keV}$ and $69.28 \mathrm{keV}$ respectively.

and energies between 50 and $100 \mathrm{keV}$ [33]. For Compton scattering, the dominant interaction process for low $\mathrm{Z}$ values and energies used in medical CT applications, the approximated cross section in these ranges deviated less than $2.3 \%$.

The model deviated more for effective atomic numbers above 10 . The substances with effective atomic numbers above 10 were solutions of $\mathrm{CaCl}_{2}$. We believe that the relative higher deviation might be explained by the hygroscopic character of $\mathrm{CaCl}_{2}$. If we assume that these substances already consisted partly out of bonded water before the solution, the calculated effective atomic numbers would have been lower, resulting in a smaller deviation from the fitting line as presented in Fig. 7. Using this assumption, the effective atomic numbers of the other substances deviated between -1.0 and $+11.1 \%$ (mean $6.3 \pm 3.5 \%$ ) and the effective electron densities deviated between -2.3 and $-0.7 \%$ (mean $-1.6 \pm 0.6 \%$ ). In addition, we argue that the model has been optimized for effective atomic numbers around oxygen $(Z=8)$, which may also explain the relative large deviations found at high effective atomic numbers.

A possible application of dual energy tissue characterization has been shown in attenuation correction of PET/CT [27]. In addition, the added value of dual energy computed tomography has been shown in the characterization of coronary atherosclerotic plaque [40], the discrimination of renal lesion proxies [41], myocardial perfusion [42,43] and pulmonary embolism [44]. Another possible application lies within the field of radiotherapy treatment planning, the information about the electron density in a human body plays an important role there [37]. Especially in treatment planning for proton and heavy-ion radiotherapy, the electron density is indispensable in order to predict the range of the particle beams in the body [38]. To our knowledge, only one study to date has assessed a method of electron density 
Table 316 substances used to assess the model with their mass density $\left(\rho_{m}\right)$, calculated effective electron densities $\left(\hat{\rho}_{e}{ }^{\prime}\right)$, measured effective electron densities $\left(\hat{\rho}_{e}\right)$ and deviation.

\begin{tabular}{|c|c|c|c|c|}
\hline Substance & $\rho_{\mathrm{m}}\left[\mathrm{g} / \mathrm{cm}^{3}\right]$ & $\rho_{\mathrm{e}}^{\prime}\left[10^{23} \mathrm{e} / \mathrm{cm}^{3}\right]$ & $\widehat{\rho}_{e}\left[10^{23} \mathrm{e} / \mathrm{cm}^{3}\right]$ & Error $\widehat{\rho}_{e}[\%]$ \\
\hline Pentane & 0.6262 & 2.195 & $2.15 \pm 0.07$ & -2.2 \\
\hline Hexane & 0.6603 & 2.307 & $2.27 \pm 0.07$ & -1.8 \\
\hline Heptane & 0.6837 & 2.383 & $2.33 \pm 0.07$ & -2.3 \\
\hline Decane & 0.7300 & 2.534 & $2.48 \pm 0.07$ & -2.3 \\
\hline Methanol & 0.7914 & 2.677 & $2.66 \pm 0.08$ & -0.7 \\
\hline Ethanol & 0.7893 & 2.683 & $2.65 \pm 0.08$ & -1.2 \\
\hline 1-Propanol & 0.8035 & 2.738 & $2.70 \pm 0.08$ & -1.5 \\
\hline 2-Propanol & 0.7855 & 2.676 & $2.63 \pm 0.08$ & -1.6 \\
\hline polyethyleenglycol 200 & 1.124 & 3.708 & $3.64 \pm 0.08$ & -1.9 \\
\hline Glycerol & 1.2613 & 4.124 & $4.09 \pm 0.09$ & -0.8 \\
\hline$\beta-D(+)$ glucose $(50 \%)$ & $1.151 \pm 0.003$ & $3.796 \pm 0.010$ & $3.75 \pm 0.09$ & -1.3 \\
\hline distilled water & $1.015 \pm 0.006$ & $3.393 \pm 0.020$ & $3.32 \pm 0.08$ & -2.2 \\
\hline $\mathrm{CaCl}_{2}\left(\mathrm{H}_{2} \mathrm{O}\right)_{2}(8.11 \%)$ & $1.059 \pm 0.002$ & $3.515 \pm 0.007$ & $3.49 \pm 0.09$ & -0.7 \\
\hline $\mathrm{CaCl}_{2}\left(\mathrm{H}_{2} \mathrm{O}\right)_{2}(16.85 \%)$ & $1.095 \pm 0.002$ & $3.611 \pm 0.007$ & $3.69 \pm 0.10$ & 2.3 \\
\hline $\mathrm{CaCl}_{2}\left(\mathrm{H}_{2} \mathrm{O}\right)_{2}(26.32 \%)$ & $1.1358 \pm 0.0005$ & $3.723 \pm 0.002$ & $3.82 \pm 0.10$ & 2.7 \\
\hline $\mathrm{CaCl}_{2}\left(\mathrm{H}_{2} \mathrm{O}\right)_{2}(60 \%)$ & $1.250 \pm 0.002$ & $4.032 \pm 0.006$ & $4.26 \pm 0.11$ & 5.7 \\
\hline
\end{tabular}

mapping using DECT for application to treatment planning with heavy particles [38]. Their method was based on a study on a synchrotron system, showing the potential to improve the precision of treatment planning for heavy-ion and proton radiotherapy. However, we used a more practical approach by using a standard commercially available scanner, showing that implementation of this technique is more feasible. However, in order to fully assess its clinical application, the method should be further investigated on an anthropomorphic phantom to determine whether the method is accurate enough for implementation in radiotherapy planning, especially proton and heavy particle radiotherapy.

In conclusion, we have validated a model for the assessment of effective atomic numbers and effective electron densities from DECT in DSCT with a high accuracy.

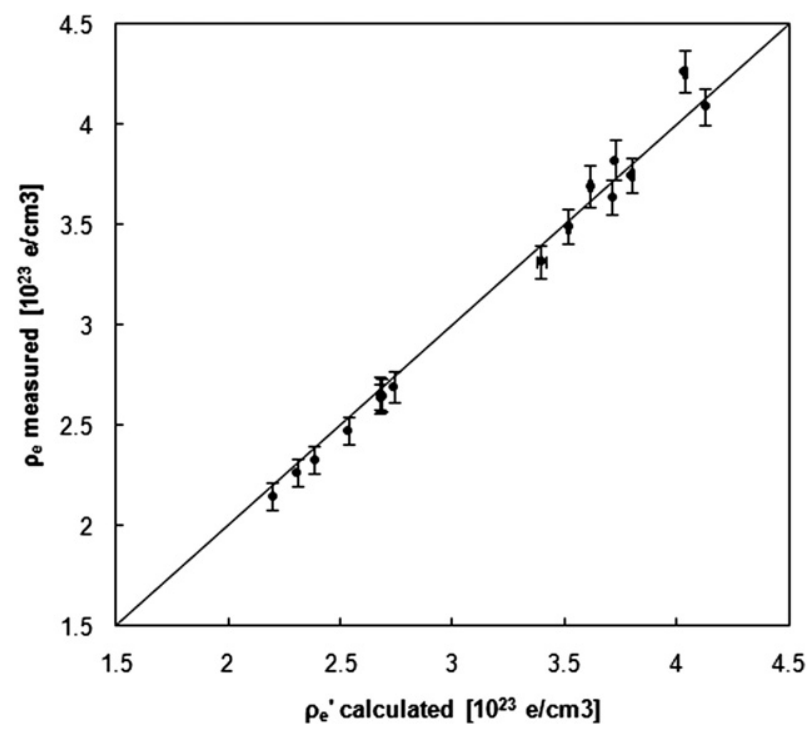

Figure 8 Measured effective electron densities ( $\rho_{e}$ measured, $\widehat{\rho}_{e}$ ) of all substances (Table 3 ) versus the corresponding calculated effective electron densities ( $\rho_{e}^{\prime}$ calculated).
The model can be used as an accurate tool for tissue characterization in DECT.

\section{References}

[1] Kalender WA, Buchenau S, Deak P, Kellermeier M, Langner O, van Straten $M$, et al. Technical approaches to the optimization of CT. Phys Med 2008;24:71-9.

[2] Chinnaiyan KM, McCullough PA, Flohr TG, Wegner JH, Raff GL. Improved noninvasive coronary angiography in morbidly obese patients with dual-source computed tomography. J Cardiovasc Comput Tomogr 2009;3:35-42.

[3] Mendler MH, Bouillet P, Le Sidaner A, Lavoine E, Labrousse F, Sautereau $D$, et al. Dual-energy CT in the diagnosis and quantification of fatty liver: limited clinical value in comparison to ultrasound scan and single-energy $\mathrm{CT}$, with special reference to iron overload. J Hepatol 1998;28:785-94.

[4] Crone-Münzebrock W, Carl UM. Dual-energyCT-scan quantification of recalcification in osteolyses of the vertebral body due to mammary carcinomas in the course of antineoplastic treatment. Clin Exp Metastasis 1990;8:173-9.

[5] Cann CE, Gamsu G, Birnberg FA, Webb WR. Quantification of calcium in solitary pulmonary nodules using single- and dualenergy CT. Radiology 1982;145:493-6.

[6] Rutherford RA, Pullan BR, Isherwood I. Measurement of effective atomic number and electron density using an EMI scanner. Neuroradiology 1976;11:15-21.

[7] Vetter JR, Perman WH, Kalender WA, Mazess RB, Holden JE. Evaluation of a prototype dual-energy computed tomographic apparatus. II. Determination of vertebral bone mineral content. Med Phys 1986;13:340-3.

[8] Kalender WA. New developments in bone density measurement by quantitative computer tomography. Radiologe 1988; 28:173-8.

[9] Flohr TG, McCollough CH, Bruder H, Petersilka M, Gruber K, Süß C, et al. First performance evaluation of a dual-source CT (DSCT) system. Eur Radiol 2006;16:256-68.

[10] Hazirolan T, Akpinar B, Unal S, Gumruk F, Haliloglu M, Alibek S. Value of Dual Energy Computed Tomography for detection of myocardial iron deposition in Thalassaemia patients: initial experience. Eur J Radiol 2008;68:442-5. 
[11] Ruzsics B, Lee H, Zwerner PL, Gebregziabher M, Costello P, Schoepf UJ. Dual-energy CT of the heart for diagnosing coronary artery stenosis and myocardial ischemia-initial experience. Eur Radiol 2008;18:2414-24.

[12] Boll DT, Merkle EM, Paulson EK, Mirza RA, Fleiter TR. Calcified vascular plaque specimens: assessment with cardiac dualenergy multidetector CT in anthropomorphically moving heart phantom. Radiology 2008;249:119-26.

[13] Matlaga BR, Kawamoto S, Fishman E. Dual source computed tomography: a Novel technique to determine stone Composition. Urology 2008;72:1164-8.

[14] Stolzmann P, Scheffel H, Rentsch K, Schertler T, Frauenfelder T, Leschka $S$, et al. Dual-energy computed tomography for the differentiation of uric acid stones: ex vivo performance evaluation. Urol Res 2008;36:133-8.

[15] Takahashi N, Hartman RP, Vrtiska TJ, Kawashima A, Primak AN, Dzyubak OP, et al. Dual-energy CT iodine-subtraction virtual unenhanced technique to detect urinary stones in an iodinefilled collecting system: a phantom study. Am J Roentgenol 2008; 190:1169-73.

[16] Grosjean R, Sauer B, Guerra RM, Daudon M, Blum A, Felblinger $\mathrm{J}$, et al. Characterization of human renal stones with MDCT: advantage of dual energy and limitations due to respiratory motion. Am J Roentgenol 2008;190:720-8.

[17] Graser A, Johnson TR, Bader M, Staehler M, Haseke N, Nikolaou K, et al. Dual energy CT characterization of urinary calculi: initial in vitro and clinical experience. Invest Radiol 2008;43:112-9.

[18] Primak AN, Fletcher JG, Vrtiska TJ, Dzyubak OP, Lieske JC, Jackson $M E$, et al. Noninvasive differentiation of uric acid versus non-uric acid kidney stones using dual-energy CT. Acad Radiol 2007;14:1441-7.

[19] Scheffel H, Stolzmann P, Frauenfelder T, Schertler T, Desbiolles L, Leschka S, et al. Dual-energy contrast-enhanced computed tomography for the detection of urinary stone disease. Invest Radiol 2007;42:823-9.

[20] Persson A, Jackowski C, Engström E, Zachrisson H. Advances of dual source, dual-energy imaging in postmortem CT. Eur J Radiol 2008;68:446-55.

[21] Sun C, Miao F, Wang XM, Wang T, Ma R, Wang DP, et al. An initial qualitative study of dual-energy $C T$ in the knee ligaments. Surg Radiol Anat 2008;30:443-7.

[22] Boll DT, Merkle EM, Paulson EK, Fleiter TR. Coronary stent patency: dual-energy multidetector CT assessment in a pilot study with anthropomorphic phantom. Radiology 2008;247: 687-95.

[23] Torikoshi M, Tsunoo T, Sasaki M, Endo M, Noda Y, Ohno Y, et al. Electron density measurements with dual-energy $x$-ray $C T$ using synchrotron radiation. Phys Med Biol 2003;48:673-85.

[24] Bazalova M, Carrier JF, Beaulieu L, Verhaegen F. Tissue segmentation in Monte Carlo treatment planning: a simulation study using dual-energy CT images. Radiother Oncol 2008;86: 93-8.

[25] Michael GJ. Tissue analysis using dual energy CT. Aus Phys Eng 1992;15:75-87.

[26] Bazalova M, Carrier JF, Beaulieu L, Verhaegen F. Dual-energy CT-based material extraction for tissue segmentation in Monte Carlo dose calculations. Phys Med Biol 2008;53:2439-56.

[27] Rehfeld NS, Heismann BJ, Kupferschläger J, Aschoff $P$, Christ G, Pfannenberg $A C$, et al. Single and dual energy attenuation correction in PET/CT in the presence of iodine based contrast agents. Med Phys 2008;35:1959-69.
[28] Mahnken AH, Stanzel S, Heismann B. Spectral rhoZ-projection method for characterization of body fluids in computed tomography: ex vivo experiments. Acad Radiol 2009;16: 763-9.

[29] Heismann BJ, Leppert J, Stierstorfer K. Density and atomic number measurements with spectral $\mathrm{x}$-ray attenuation method. J Appl Phys 2003;94:2073-80.

[30] Yang M, Virshup G, Clayton J, Zhu XR, Mohan R, Dong L. Theoretical variance analysis of single- and dual-energy computed tomography methods for calculating stopping power ratios of biological tissues. Phys Med Biol 2010;55:1343-62.

[31] Yang M, Zhu X, Mohan R, Dong L. In vivo measurement of proton stopping power ratios in patients using dual energy computed tomography. Med Phys 2009;36:2757.

[32] Manohara SR, Hanagodimath SM, Thind KS, Gerward L. On the effective atomic number and electron density: a comprehensive set of formulas for all types of materials and energies above $1 \mathrm{keV}$. Nucl Instr Meth Phys Res B 2008;266:3906-12.

[33] Berger MJ, Hubbell JH, Seltzer SM, Chang J, Coursey JS, Sukumar R, et al. XCOM: Photon Cross Section Database (version 1.4). Gaithersburg, MD: National Institute of Standards and Technology. [Online] Available: http://physics.nist. gov/xcom; 2009.

[34] Henson PW. Determination of electron density, mass density and calcium fraction by mass of soft and osseous tissue by dual energy CT. Aus Phys Eng 1989;12:3-10.

[35] Hawkes DJ, Jackson DF. An accurate parametrisation of the $x$ ray attenuation coefficient. Phys Med Biol 1980;25:1167-71.

[36] McCullough EC. Photon attenuation in computed tomography. Med Phys 1975;2:307-20.

[37] Seco J, Evans PM. Assessing the effect of electron density in photon dose calculations. Med Phys 2006;33:540-52.

[38] Jiang $\mathrm{H}$, Seco J, Paganetti H. Effects of Hounsfield number conversion on CT based proton Monte Carlo dose calculations. Med Phys 2007;34:1439-49.

[39] Kijewski PK, Bjarngard BE. Correction for beam hardening in computed tomography. Med Phys 1978;5:209-14.

[40] Henzler T, Porubsky S, Kayed H, Harder N, Krissak UR, Meyer M, et al. Attenuation-based characterization of coronary atherosclerotic plaque: comparison of dual source and dual energy CT with single-source CT and histopathology. Eur J Radiol 2010 Aug 30 [Epub ahead of print].

[41] Karlo C, Lauber A, Götti RP, Baumüller S, Stolzmann P, Scheffel $\mathrm{H}$, et al. Dual-energy CT with tin filter technology for the discrimination of renal lesion proxies containing blood, protein, and contrast-agent. An experimental phantom study. Eur Radiol 2010 Aug 15 [Epub ahead of print].

[42] Kang DK, Schoepf UJ, Bastarrika G, Nance Jr JW, Abro JA, Ruzsics B. Dual-energy computed tomography for integrative imaging of coronary artery disease: principles and clinical applications. Semin Ultrasound CT MR 2010;31:276-91.

[43] Ko SM, Choi JW, Song MG, Shin JK, Chee HK, Chung HW, et al. Myocardial perfusion imaging using adenosine-induced stress dual-energy computed tomography of the heart: comparison with cardiac magnetic resonance imaging and conventional coronary angiography. Eur Radiol 2010 Jul 25 [Epub ahead of print].

[44] Lu GM, Wu SY, Yeh BM, Zhang LJ. Dual-energy computed tomography in pulmonary embolism. Br J Radiol 2010;83:707-18.

[45] Johnson TR, Krauss B, Sedlmair M, Grasruck M, Bruder H, Morhard D, et al. Material differentiation by dual energy CT: initial experience. Eur Radiol 2007;17:1510-7. 